Poetry

\title{
Palliative care and poetry
}

\section{Introduction}

"Anima in motion, to infinity, with sense. I feel worthy until the last moments; I wish more than sighs: life."

User embracement is an action of approach. It means "being with" and "being near", in other words, it is an attitude of inclusion, of being related to something or someone. It is a lightweight technology that comprises the relationship between the teams and the users and aims to reverse the logic of organization and operation of health service. Its principles are: ensuring universal access, reorganizing the work process based on a multidisciplinary team and qualifying the relationship between health professional and patient. ${ }^{1}$

Thus, the term "user embracement" is understood in both spatial dimension (a formal reception and a comfortable environment) and administrative dimension (transfer to specialized services). The poetic language must be used as a tool for user embracement in the context of Palliative Care, as it associates care and affection, providing a sensitive and human communication channel. It is a toast to life because it becomes one of the essential elements for an adequate palliative care, which makes all the difference in the countless forgotten, remembered or released stories. The poetic language associated with different expressions (photograph, fine art, music etc.) and used in the hospital daily life provides favorable results to the self-esteem and the preservation of the spirit of those who are being assisted by the health team. ${ }^{2}$

\section{The care}

Rudeness is like a petal that is detached from the rose in its natural state of beauty.

\section{The patient}

A slight sadness in the uncertainty

A word, only: the one for sure

A warmth, maybe some comfort

Something that cannot be translated

A delicate gesture beyond the petals spread

His black, assertive eyes

Slightly sad reveries

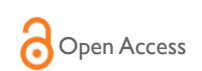

CrossMark
Volume I Issue I - 2017

Andrea Geórgia de Souza Frossard

Professor at the National Cancer Institute José Gomes de Alencar, Brazil

Correspondence: Andrea Geórgia de Souza Frossard, Post doctor in Humanities, Professor at the National Cancer Institute José Gomes de Alencar, Palliative Care Unit, Rio de Janeiro, Brazil, Email afrossard@inca.gov.br

Received: March 14, 2017| Published: May 05, 2017

\section{The Uncertainty}

In the morning, the swing without a net

Nausea without vomiting

In the afternoon, soft, almost absent tears

At night, a dream full of intimate glances

He awakens with his mouth open and dry

Naked body

Clear robes on the floor

Windows slightly open, waiting

\section{Acknowledgements}

None.

\section{Conflict of interest}

The author declares no conflict of interest.

\section{References}

1. Franco Túlio Batista, Bueno Wanderlei Silva, Merhy Emerson Elias. O acolhimento e os processos de trabalho em saúde: o caso de Betim, Minas Gerais, Brasil. Cad Saúde Pública. 1999;15(2):345-353.

2. Frossard A. Vidas em partidas. Quartet, Rio de Janeiro, Brazil: Springer; 2014. 